\title{
Effects of Early Malnutrition on Mental System, Metabolic Syndrome, Immunity and the Gastrointestinal Tract
}

\author{
Zhixiong $\mathrm{HE}^{1,2)}$, Zhihong SUN ${ }^{1,2) *}$, Shimin $\mathrm{LIU}^{3)}$, Qingli ZHANG ${ }^{1,4)}$ and Zhiliang TAN ${ }^{1) * *}$ \\ ${ }^{1)}$ Key Laboratory for Agro-Ecological Processes in Subtropical Region, Institute of Subtropical Agriculture, CAS, Hunan, 410125, \\ ${ }^{2)}$ Graduate School of the Chinese Academy of Sciences, Beijing 100049, P.R. China, ${ }^{3)}$ The University of Western Australia, Perth 6009, \\ Australia and ${ }^{4}$ Northwest Sci-Tech University of Agriculture \& Forestry, Yanglin 712100, P.R. China
}

(Received 12 February 2009/Accepted 4 May 2009)

\begin{abstract}
The notion of how malnutrition early in life affects ontogenesis has evolved considerably since the mid-1960s. Since then, there have been many studies on the effects of early malnutrition. Nutritional and metabolic exposure during critical periods in early human and animal development may have long-term programming effects in adulthood. This is supported by evidence from epidemiological studies, numerous animal models and clinical intervention trials. In this paper, we review the effects of early malnutrition on cognitive function, metabolic syndrome, immunity and the gastrointestinal tract, as well as possible underlying mechanisms, and consider diarrhoeal disease and poor cognitive function as examples for understanding the interrelation of the harmful effects caused by early malnutrition. Previous studies on early malnutrition have mainly concentrated on humans and rats. Therefore, the main aim of the present review was to give animal scientists a clear understanding of the harmful effects of early malnutrition on animal growth and animal production, and to help identify appropriate feeding techniques to prevent early malnutrition.

KEY WORDS: early malnutrition, gastrointestinal development, immunity, metabolic syndrome.
\end{abstract}

J. Vet. Med. Sci. 71(9): 1143-1150, 2009

\section{Important nutrients during fetal and neonatal development}

While all nutrients are important for cell growth and body development, some appear to have more important effects especially during the last trimester and early neonatal period. These nutrients include protein, zinc, iron, copper, selenium, iodine, folate, vitamin A, choline and long-chain polyunsaturated fatty acids (LC-PUFA) [32]. The importance of these nutrients has been investigated primarily through nutrient-deficiency studies and through knowledge of their possibly specific biochemical pathways that affect growth and function.

Protein-energy malnutrition is the most common cause of early stunting and later chronic disease. A severe state of protein-energy malnutrition has been shown to significantly diminish body weight, body length, and intestine length of rats compared with control animals $[64,77]$. Intestinal weight and total DNA were similarly diminished in malnourished rats [37]. Fetal and early postnatal protein malnutrition had a long-term negative impact on rat liver and muscle mitochondria of rat [60]. Protein malnutrition in weanling murine systems elicited early elevations in blood glucocorticoid levels to a magnitude reminiscent of critical illness and multiple trauma [52].

Micronutrients including zinc, iron, copper, iodine and selenium are essential in fetal and neonatal development. With zinc deficiency, the individual of rat is more susceptible to toxin-producing bacteria or pathogens that activate

\footnotetext{
* This author contributed equally to this work as co-first author.

**Correspondence to: Dr. Tan, Z., Key Laboratory for Agro-Ecological Processes in Subtropical Region, Institute of Subtropical Agriculture, CAS, Hunan, 410125, P. R. China.

e-mail: jinzhu20070930@yahoo.cn
}

guanylate and adenylate cyclases, which stimulate chloride secretion, to produce diarrhea disease and reduce the absorption of nutrients [88]. The zinc concentration might regulate insulin-like growth factor I and growth hormone receptor gene expression $[78,79,82]$. Perinatal iron deficiency produced an altered neurochemical profile of the developing hippocampus in children [68] and significantly altered the development of myelination around the hippocampus in rat [92]. Fetal and neonatal iron deficiency resulted in diminished oxidative metabolism in the hippocampus and frontal cortex in rat [20], increased intracellular neuronal glutamate concentrations in rat [70], and reduced striatal dopamine concentrations $[6,89]$. Copper is an essential divalent cation for proteins involved in brainenergy metabolism, dopamine metabolism, antioxidant activity, and iron accretion in the fetal and neonatal brain [32]. Gestational copper deficiency appeared to affect the developing fetal cerebellum in rat, which would have longterm effects on motor function, balance and coordination [61]. Iodine deficiency reduced the size of the thyroid in rat [10]. Selenium has been shown to be essential for optimal thyroid hormone metabolism [84].

Other nutrients such as LC-PUFA and vitamins also have important effects on growth and physiological function in animals and humans. Fats, particularly docosahexaenoic acid, have been shown to be potent neurobiological agents that affect neuronal membrane structure, synaptogenesis and myelination [86]. Low maternal vitamin B12 and high folate status could contribute to the epidemic of adiposity and type 2 diabetes in India [93].

All of these studies showed that an individual nutrient deficiency resulted in the impairment of multiple systems and the development of the organism was influenced by var- 
ious nutrients simultaneously.

\section{Nutrition and mental system development}

In the mid-1960s, the relationship between nutrition and mental system development had become a focus of research. The evidence is quite clear that nutrients are vital to mental system development, especially during the late fetal and early neonatal life period. During this period, regions such as the hippocampus, the visual and auditory cortices, and the striatum undergo rapid development characterized by the morphogenesis and synaptogenesis that make them functional [54, 83]. For any given region, early malnutrition have a greater effect on cell proliferation, thereby affecting cell number $[81,91]$.

The harmful impact of early malnutrition on morphological development of the nervous system has been confirmed in previous studies. Early malnutrition obviously reduced the size of the brain $[29,23]$. The cerebral cortex, which is the brain region that is most closely linked to cognitive and intellectual functioning, showed reductions in volume [7] and width [29] after neonatal malnutrition. Neuroanatomical studies using Golgi staining techniques showed that malnutrition caused a significant disruption in pyramidal cells of the cerebral cortex, a reduction in the density of cortical dendritic spines, and a decrease in both the width of cortical cells and the complexity of the dendritic branching of the cortex [44]. For any given region, early malnutrition reduced the speed of cell proliferation and the total cell number in rat [81].

Some studies showed that morphologic and neurological parameters of the brain could recover with nutritional rehabilitation after malnutrition. The smaller volume and width of cerebral cortex of rat were normalized after later nutritional rehabilitation [23]. The increase in cell packing and dendritic branching observed in the cortex in rat during early malnutrition was reversed by subsequent nutritional rehabilitation [15].

However, the reduced number of cortical dendrites in synaptic spines, as a neural aberration in the cortex, failed to recover with later nutritional rehabilitation [44]. Moreover, the reduction in brain myelin in rat, which might be indicative of a reduction in the number of myelinated axons in the brain, was not normalized after nutritional rehabilitation [90]. Recently, there was also a suggestion that chronic protein malnutrition in rat induced abnormalities in the density and morphology of the soma of vasopressive and vasoactive intestinal polypeptide neurons [75].

Nutrients can affect not only morphological development, but also neurochemistry and neurophysiology. Neurochemical alterations include changes in neurotransmitter synthesis, receptor synthesis, and neurotransmitter reuptake mechanisms $[6,70]$. Neurophysiologic changes reflect changes in metabolism and signal propagation. The changes across all 3 venues ultimately result in altered neuronal behavior. Early malnutrition reduced the number of large fibers in the adult corticospinal tract of rat [66]. Learning and memory in early postnatal protein-malnourished rats were investigated in the Morris water maze. The results showed no impairment of learning or memory in malnourished rats, but did show an increased latency and distance traveled to find the submerged platform [30]. Early iron deficiency also affected locomotor behavior and water maze performance of rat [12]. With regard to behavioral selfselection, rats could choose an adaptive form when recovering from protein malnutrition [14].

In human studies, malnourished children have been described as having less activity, more anxiety, and less imagination in solving a problem than well-nourished children [5], and exhibit decreased exploration of the environment, as well as decreased verbal activity [31]. Malnourished children have been reported to be deficient in arithmetic, standardized reading and vocabulary, as well as literacy and general knowledge compared to controls [13, 46]. Furthermore, it has been shown that low-birth-weight children born to malnourished women might have deficits in mental and psychomotor development indexes [11, 33].

From above, it is quite clear that malnutrition limited to the prenatal period is not only sufficient to have a permanent effect on brain structure but also causes enduring changes in behavior, while postnatal malnutrition produces temporary morphological effects and permanent alterations in behavior. Therefore, the effects of early malnutrition on behavior can not be recovered. The conclusion was also supported by the evidence as followed. Early malnutrition could relatively directly predispose to externalizing behavior problems by impairing brain mechanisms such as those in the prefrontal cortex that are thought to regulate emotion and inhibit impulsive aggressive behavior [67], malnutrition could also predispose to externalizing behavior problems more indirectly by impairing cognitive functioning, which in turn predisposes to externalizing behavior problems [47]. Poor cognitive ability has been found consistently to predispose to externalizing behavior problems [24].

\section{Early malnutrition and metabolic syndrome}

Metabolic syndrome, a cluster of cardiovascular risk factors that includes diabetes, hypertension, and obesity, is now recognized as a major health problem in Western countries. Extensive logical and laboratory evidence has indicated that a suboptimal maternal environment such as malnutrition during fetal and neonatal development in both humans and experimental animals affects the offspring's susceptibility to the later development of altered carbohydrate metabolism $[63,94]$. Furthermore, many studies have suggested that a low birth weight was associated with an increased risk of the metabolic syndrome in adulthood $[65,68]$, although it has also been reported that neither prenatal exposure to famine nor reduced birth weight was associated with a greater prevalence of the metabolic syndrome [21].

Studies have indicated that impaired glucose tolerance and insulin resistance are the two major causes of diabetes [36]. A decrease in the mtDNA level in peripheral blood preceded the development of diabetes [42]. In addition to qualitative changes, quantitative changes in plasma insulin 
concentrations and mitochondrial DNA (mtDNA) seem to be associated with insulin resistance and type 2 diabetes. When children were protein-malnourished, in early life (6 weeks-3 months) glucose tolerance was increased and plasma insulin concentrations were reduced, indicating increased insulin sensitivity $[45,59]$. While there was no difference in glucose tolerance at age 1 year, glucose tolerance was impaired at 15 months and at 17 months in male rats, which may reflect the emergence of diabetes [35]. Insulin concentrations in male rat at 17 months were approximately doubled, clearly indicating insulin resistance at this stage [62]. In addition, the mtDNA content of the liver and skeletal muscle in rat were reduced in fetal and early postnatal malnourished rats even when they were provided nutritional rehabilitation after weaning [60]. This result indicated that early malnutrition causes long-lasting changes in mitochondria that might contribute to the development of alterations in insulin action in later life. The hypothesis that several mechanisms including genomic imprinting that change mtDNA content according to the nutritional status of fetal or early development was stated (Fig. 1) [43].

What is the link between nutrition and metabolic syndrome? According to the "thrifty phenotype" hypothesis, a poor nutritional condition in early life programs a phenotype in later life, in a way that is beneficial to survival under poor nutritional conditions but detrimental when nutrition is abundant [34]. If we also consider insulin resistance and glucose tolerance, three major themes have been proposed: effects of mild to moderate hyperglycemia, effects of compensatory hyperinsulinemia, and effects of unbalanced pathways of insulin action [51].
Hyperglycemia, largely below the diabetic threshold, may lead to a variety of effects that are usually associated with diabetes. For example, a moderate controlled hyperglycemia can lead to an increased non-oxidative glucose disposal rate that contributes to glucose tolerance after oral glucose ingestion [74].

A more important mechanism may be compensatory hyperinsulinemia. The maintenance of normal glucose homeostasis after a meal requires the stimulation of glucose uptake by muscle, which is responsible for the disposal of $80 \%$ to $90 \%$ of the ingested glucose load, and the suppression of endogenous glucose production, over $80 \%$ of which is derived from the liver. Moreover, compensatory hyperinsulinemia refers to an insulin-resistant condition in which the ability of insulin to augment glucose uptake and inhibit hepatic glucose production is impaired. The resultant hyperglycemia stimulates beta cells, which secrete large amounts of insulin after meals [71]. In addition, experimental evidence has substantiated that insulin resistance and compensatory hyperinsulinemia are increased in patients with essential hypertension [72].

Metabolic syndrome is associated with insulin resistance, but is neither a consequence of insulin resistance alone nor a direct consequence of the lack of insulin action. Low birth weight has been associated with specific changes in muscle insulin-signaling protein expression [58]. Recently, great progress has been made in understanding the signal transduction pathways that control the classical metabolic actions of insulin to promote glucose uptake in skeletal muscle and adipose tissue through translocation of the insulinresponsive glucose transporter [17]. The two major pathways for insulin signaling are the phosphatidylinositol 3-

Maternal malnutrition

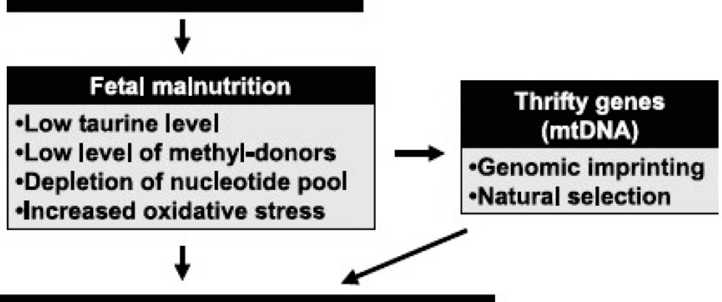

Poor initial condition of mitochondrial function

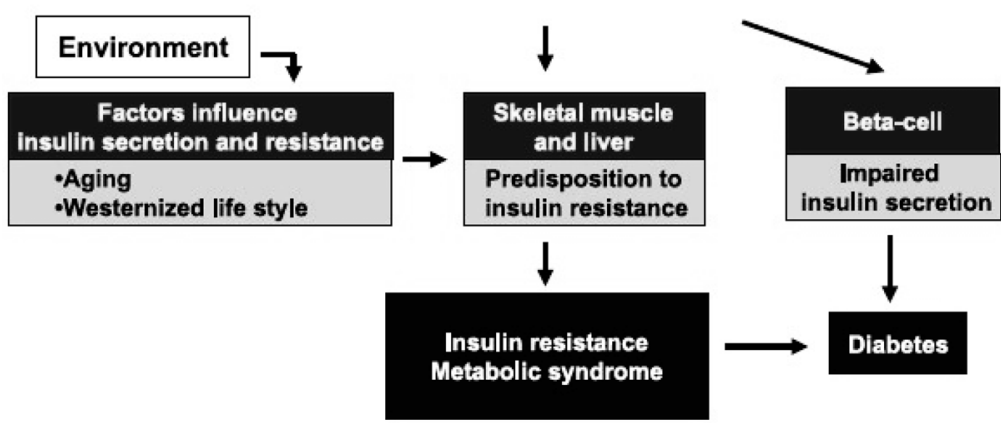

Fig. 1. General outline of mitochondrial hypothesis. 
kinase $(\mathrm{PI} 3 \mathrm{~K})$ and mitogen-activated protein kinase (MAPK) pathways. The balance between the NO-dependent vasodilatory actions and endothelin-1-dependent vasoconstrictive actions of insulin is regulated by PI3K- and MAPK-dependent signaling in vascular endothelium, respectively. Under insulin-resistant conditions, pathwayspecific impairment of PI3K-dependent signaling and enhanced MAPK-dependent signaling in vascular endothelium might contribute to reciprocal relationships between endothelial dysfunction and insulin resistance that underlie the close associations between metabolic and cardiovascular diseases [53]. Thus, insulin resistance which may be the result of early malnutrition could lead not only to severe diabetes but also hypertension, obesity and other cardiovascular diseases [50, 60, 73].

\section{Early malnutrition and immunity}

Nutrition is a critical determinant of the immune response, and malnutrition is the most common cause of immunodeficiency worldwide. Malnutrition in early life, particularly in the perinatal period, is critical for the immune competency of animals because it affects the immune system not only with regard to immediate function but also a long-term modulation [22]. Malnutrition usually permanently stunts the development of lymphoid organs. In rats, for example, malnutrition in dams caused impairment in the thymus [77]. Secondary to thymic atrophy, the production of thymic hormones that are critical for the differentiation of $\mathrm{T}$ lymphocytes was reduced, especially in protein-calorie malnutrition and zinc deficiency [49]. Rats from dams on a protein-deficient diet during gestation showed a permanent negative impact on growth and the size of organs including the thymus and spleen, even though they were given a wellbalanced diet after weaning [48].

Immune responses were also influenced by early malnutrition. In protein-energy malnutrition, extensive dysfunction of the macrophage proinflammatory cytokine network and nuclear factor- (kappa) B regulation, which mediates innate immunity, was discovered in mouse [3]. Other studies have shown a loss of corticomedullary differentiation, fewer lymphoid cells, and enlarged, degenerated, and occasionally calcified Hassall bodies [16]. In addition, proteinenergy malnutrition was associated with a significant impairment of cell-mediated immunity, phagocyte function, complement system, secretory immunoglobulin A antibody concentration, and cytokine production in children [27]. Dietary deficiencies in specific nutrients profoundly weakened cell-mediated immune responses in humans [76] and low-birth-weight infants showed a prolonged impairment of cell-mediated immunity [16]. Protein malnutrition also reduced antioxidant levels, impaired immune functions and increased sensitivity to opportunistic infections and septic shock [8, 19]. Malnutrition resulted in lower inducible nitric oxide synthase activity in the spleen and liver of malnourished mice and a failure of lymph node barrier function, which led to the development of visceral leishmaniasis after $L$. donovani infection that may have been related to the excessive production of prostaglandin $\mathrm{E}_{2}$ and decreased levels of interleukin-10 and nitric oxide [4]. Therefore, hostdefense mechanisms influenced by the immune system are impaired.

\section{Early malnutrition on development of the gastrointestinal tract}

After birth, the neonate must quickly adapt to transition from intrauterine umbilical nourishment to oral nutrient assimilation. Consequently, the rapid growth and functional development of the gastrointestinal tract during the neonatal period are critical for optimal somatic growth and survival [26]. This increased functional demand on the infantile gastrointestinal tract has been associated with a disproportionately high rate of metabolic activity: the gastrointestinal tract represents only $5-7 \%$ of body mass, yet consumes roughly $15-20 \%$ of the neonate's oxygen needs [28]. In addition to the absolute nutrient requirements, the functional demands of the gastrointestinal tract might also significantly affect the availability of nutrients to peripheral tissues [26]. In addition, the ontogeny of the intestine is critically influenced by the mother's diet during gestation as well as during the nursing period. Some of the diet-associated changes in nutrient uptake resulting from the mother's diet during pregnancy could be corrected by dietary interventions introduced after birth [38]. Therefore, early nutrition including during the fetal and early postnatal period is particularly important, and the lack of any nutrient may delay the growth of the intestine and other tissues.

The neonate is immunologically naive and very susceptible to infection and damage from harmful antigens. Early nutrition plays an important role in protecting the developing intestine from harmful agents and in modulating immune responses following antigenic challenge [40]. In addition, the intestine and its associated cells require nutrients to support their proliferation and differentiation as well as the secretion of enzymes, proteins, and other materials [41]. The rates of enterocyte proliferation and migration are affected by a variety of factors. An overt nutrient deficiency, most notably for zinc [80], vitamin A [85], and cyanocobalamin (B12) [95], will affect intestinal physiology. Glutathione is a crucial antioxidant in the gastrointestinal mucosa that is also formed from glutamine [55, 72]. Dietary glutamine probably contributes significantly to intestinal glutathione synthesis [25]. It has been shown that dietary fatty acids directly affect the profile of fatty acids in the gastrointestinal tract of rat [57].

Abnormalities in gastrointestinal function [malabsorption, maldigestion, pancreatic dysfunction, and protein-losing enteropathy] have been shown to be associated with malnutrition [1]. A severe state of protein-energy malnutrition significantly diminished the intestine length of rats compared with control animals [77]. Intestinal weight and total DNA were similarly diminished in the malnourished rats [37]. In humans, the prevalence of micronutrient deficiencies, including zinc, folate, and the B vitamins, is especially high in Southeast Asia and sub-Saharan Africa [69], it 
might indicate that malnourished people in less-developed areas may show the poor absorption and retention of macronutrients and minerals, including zinc. Experimentally, malnourished rats absorbed less zinc than well-fed controls [88]. Alterations in the ratio of polyunsaturated to saturated fatty acids in the diet modified the age-associated changes in the intestinal uptake of glucose, and these changes occurred rapidly, progressively, and irreversibly, suggesting that the intestinal uptake of glucose was subject to critical period programming [39]. However, another study suggested that the growth, metabolism, and perhaps absorptive function of the neonatal gastrointestinal tract were not significantly affected by a short period of protein malnutrition, and protein malnutrition significantly reduced the growth of the skeletal muscle [26]. The resultant repartitioning of lean body mass in protein-malnourished neonates might manifest itself in increased basal energy and protein requirements. These might result from a reduced insulin response to feeding which would lead to chronic reduction in amino acid absorption in protein-malnourished pigs, which presumably limits substrate availability and the anabolic stimulus for skeletal muscle protein accretion [26]. Since the mechanism is unclear, further studies are needed to explain why and how early malnutrition affects the gastrointestinal tract and the growth of other tissues.

\section{Relation between malnutrition, diarrhea and cognitive function}

In developing countries, diarrhea, which is one of main results of malnutrition, is a leading cause of child morbidity and mortality. Diarrhea is caused by the interrelated effects of immunodeficiency and gastrointestinal abnormalities.

Protein-energy malnutrition has been shown to be associated with a decrease in the immunologic defense mechanisms that lead to a greater susceptibility to infection and certain infectious diseases caused by malnutrition [2]. One of the consequences of protein-energy malnutrition has been shown to be impairment of the small intestinal mucosal absorptive capacity for zinc [87]. In addition, the injection of IL-1a produced diarrhea in $66 \%$ of zinc-deficient rats, but not in any well-fed animals [18]. These results might explain the susceptibility of individuals with a compromised zinc status to infectious diarrhea. The alterations seen in the gastrointestinal tract during severe food restriction can lead to malabsorption, diarrhea, electrolyte depletion and even death [87].

Diarrhea is associated with cognitive function, in addition to immunodeficiency and gastrointestinal function abnormalities. Stunting, diarrheal disease, and parasitic infections caused mostly by malnutrition were also related to poor mental function [9]. In addition, a follow-up study that specifically addressed the possible long-term impact of early childhood diarrhea on cognitive function in later childhood suggested that childhood diarrhea was linked to deficits in cognitive abilities several years later $[9,56]$.

\section{Conclusion}

Early malnutrition can have harmful effects on the development of mental system, immune function and the gastrointestinal tract, and can cause metabolic syndrome. Thus, the harmful effects of early malnutrition are interconnected with other harmful effects.

It is well known that the development of mental system, immune function and the gastrointestinal tract are associated with animal growth and animal production. Therefore, we should give more attention to the harmful effects of early malnutrition. The key is to identify specific early malnutrition and harmful effects especial on gastrointestinal tract development under specific animal feeding mode, and find appropriate remedial feeding techniques to reduce the harmful effects of early malnutrition.

This study was supported by grants from the National Natural Science Foundation of China (No. 30600436), the Natural Science Foundation of Hunan Province (07JJ5029) and The Chinese Academy of Sciences (KSCX2-YW-N051).

\section{REFERENCES}

1. Aguilera, A., Bajo, M. A., Espinoza, M., Olveira, A., Paiva, A. M., Codoceo, R., MDa, P. G., RN, S. S., Celadilla, O., Castro, M. J. and Selgas, R. 2003. Gastrointestinal and pancreatic function in peritoneal dialysis patients: their relationship with malnutrition and peritoneal membrane abnormalities. Am. J. Kidney Dis. 42: 787-796.

2. Ambrus, Sr, J. L. and Ambrus, J. L. Jr, 2004. Nutrition and infectious diseases in developing countries and problems of acquired immunodeficiency syndrome. Exp. Biol. Med. 229: 464-472.

3. Anstead, G. M., Chandrasekar, B., Zhang, Q. and Melby, P. C. 2003. Multinutrient undernutrition dysregulates the resident macrophage proinflammatory cytokine network, nuclear factor-(kappa) B activation, and nitric oxide production. J. Leukoc. Biol. 74: 982-991.

4. Anstead, G. M., Chandrasekar, B., Zhao, W., Yang, J., Perez, L. E. and Melby, P. C. 2001. Malnutrition alters the innate immune response and increases early visceralization following leishmania donovani infection. Infect. Immun. 69: 4709-4718.

5. Barrett, D. E. and Radke-Yarrow, M. 1985. Effects of nutritional supplementation on children's responses to novel, frustrating, and competitive situations. Am. J. Clin. Nutr. 42: 102120.

6. Beards, J. L. and Connor, J. R. 2003. Iron status and neural functioning. Annu. Rev. Nutr. 23: 41-58.

7. Bedi, K. S. and Bhide, P. G. 1988. Effects of environmental diversity on brain morphology. Early Hum. Dev. 17: 107-143.

8. Beishuizen, A., Vermes, I. and Haanen, C. 1998. Endogenous mediators in sepsis and septic shock. Adv. Clin. Chem. 33: 55131.

9. Berkman, D. S., Lescano, A. G., Gilman, R. H., Lopez, S. L. and Black, M. M. 2002. Effects of stunting, diarrhoeal disease, and parasitic infection during infancy on cognition in late childhood: a follow-up study. Lancet 359: 564-571.

10. Biebinger, R., Arnold, M., Langhans, W., Hurrell, R. F. and Zimmermann, M. B. 2007. Vitamin A repletion in rats with concurrent Vitamin A and Iodine deficiency affects pituitary 
TSH [beta] gene expression and reduces thyroid hyperstimulation and thyroid size. J. Nutr. 137: 573-577.

11. Borba, J. M., Araujo, M. S., Picanco Diniz, C. W., Manhaes de Castro, R. and Guedes, R.C. 2000. Permanent and transitory morphometric changes of NADPH-diaphorase-containing neurons in the rat visual cortex after early malnutrition. Brain Res. Bull. 53: 193-201.

12. Bourque, S. L., Iqbal, U., Reynolds, J. N., Adams, M. A. and Nakatsu, K. 2008. Perinatal iron deficiency affects locomotor behavior and water maze performance in adult male and female rats. J. Nutr. 138: 931-937.

13. Brown, J. L. and Pollitt, E. 1996. Malnutrition, poverty and intellectual development. Sci. Am. 274: 38-43.

14. Cambraia, R. P. B., Vannucchi, H., Almeida, S. S. and DeOliveira, L. M. 2001. Effects of malnutrition during early lactation on development and feeding behavior under the self-selection paradigm. Nutrition 17: 455-461.

15. Carughi, A., Carpenter, K. J. and Diamond, M. C. 1989. Effect of environmental enrichment during nutritional rehabilitation on body growth, blood parameters and cerebral cortical development of rats. J. Nutr. 119: 2005-2016.

16. Chandra, R. K. 1997. Nutrition and the immune system: an introduction. Am. J. Clin. Nutr. 66: 460-463.

17. Cohen, P. 2006. The twentieth century struggle to decipher insulin signaling. Nat. Rev. Mol. Cell Biol. 7: 867-873.

18. Cui, L., Takagi, Y., Wasa, M., Iiboshi, Y., Khan, J., Nezu, R. and Okada, A. 1997. Induction of nitric oxide synthase in rat intestine by interleukin- $1 \alpha$ may explain diarrhea associated with zinc deficiency. J. Nutr. 127: 1729-1736.

19. Daly, J. M., Reynolds, J., Sigal, R. K., Shou, J. and Liberman, M. D. 1990. Effect of dietary protein and amino acids on immune function. Crit. Care Med. 18: 86-93.

20. de Deungria M., Rao, R., Wobken, J. D., Luclana, M., Nelson, C. A. and Georgieff, M. K. 2000. Perinatal iron deficiency decreases cytochrome c oxidase (CytOx) activity in selected regions of neonatal rat brain. Pediatr. Res. 48: 169-176.

21. de Rooij, S. R., Painter, R. C., Holleman, F., Bossuyt, P. M. and Roseboom, T. J. 2007. The metabolic syndrome in adults prenatally exposed to the Dutch famine. Am. J. Clin. Nutr. 86: $1219-1224$.

22. Deng, K. D. and Zhang, Y. X. 2004. Long-term modulation of the immune system by perinatal nutrition. Agric. Sci. Technol. 5: 11-16.

23. Diaz-Cintra, S., Cintra, L., Ortega, A., Kemper, T. and Morgane, P. J. 1990. Effects of protein deprivation on pyramidal cells of the visual cortex in rats of three age groups. J. Comp. Neurol. 292: 117-126.

24. Donnellan, M.B., Xiao, G. and Wenk, E. 2000. Cognitive abilities in adolescentlimited and life-course-persistent criminal offenders. J. Abnorm. Psychol. 109: 396-402.

25. Duggan, C., Gannon, J. and Walker, W. A. 2002. Protective nutrients and functional foods for the gastrointestinal tract. $\mathrm{Am}$. J. Clin. Nutr. 75: 789-808.

26. Ebner, S., Schoknecht, P., Reeds, P. and Burrin, D. 1994. Growth and metabolism of gastrointestinal and skeletal muscle tissues in protein-malnourished neonatal pigs. Am. J. Physiol. 266: 1736-1743.

27. Ekiz, C., Agaoglu, L., Karakas, Z., Gurel, N. and Yalcin, I. 2005. The effect of iron deficiency anemia on the function of the immune system. Hematol. J. 5: 579-583

28. Eldelstone, D. I. and Holzman, I. R. 1981. Gastrointestinal tract $\mathrm{O} 2$ uptake and regional blood flows during digestion in conscious newborn lambs. Am. J. Physiol. Gastrointest. Liver
Physiol. 241: 289-293.

29. Fernández, V., Pascual, R. and Ruíz, S. 1993. Early life environmental deterioration, nutrition and ontogenesis of the motor cortex in the rat: a Golgi study. Biol. Neonate. 64: 245-253.

30. Fukuda, M. T. H., Francolin-Silva, A. L. and Almeida, S. S. 2002. Early postnatal protein malnutrition affects learning and memory in the distal but not in the proximal cue version of the Morris water maze. Behav. Brain Res. 133: 271-277.

31. Gardner, J. M. and Grantham-McGregor, S. M. 1994. Physical activity, undernutrition and child development. Proc. Nutr. Soc. 53: 241-248.

32. Georgieff, M. K. 2007. Nutrition and the developing brain: nutrient priorities and measurement. Am. J. Clin. Nutr. 85: 614S-620S.

33. Grantham-McGregor, S. M., Lira, P. I., Ashworth, A., Morris, S. S. and Assuncao, A. M. 1998. The development of low birth weight term infants and the effects of the environment in northeast Brazil. J. Pediatr. 132: 661-666.

34. Hales, C. N. and Barker, D. J. P. 1992. Type 2 (non-insulin dependent) diabetes mellitus: the thrifty phenotype hypothesis. Diabetologia 35: 595-601.

35. Hales, C. N., Desai, M., Ozanne, S. E. and Crowther, N. J. 1996. Fishing in the stream of diabetes: from measuring insulin to the control of fetal organogenesis. Biochem. Soc. Trans. 24: 341-350.

36. Hales, C. N. and Ozanne, S. E. 2003. For debate: fetal and early postnatal growth restriction lead to diabetes, the metabolic syndrome and renal failure. Diabetologia 46: 1013-1019.

37. Hatch, T. F., Lebenthal, E., Branski, D. and Krasner, J. 1979. The effect of early postnatal acquired malnutrition on intestinal growth, disaccharidases and enterokinase. J. Nutr. 109: 18741879.

38. Jarocka-Cyrta, E., Perin, N., Keelan, M., Wierzbick, E., Wierzbicki, T., Clandinin, M. T. and Thomson, A. B. R. 1998. Early dietary experience influences ontogeny of intestine in response to dietary lipid changes in later life. Am. J. Physiol. Gastrointest. Liver Physiol. 275: 250-258.

39. Keelan, M., Thomson, A. B., Garg, M. L. and Clandinin, M. T. 1990. Critical period programming of intestinal glucose transport via alterations in dietary fatty acid composition. Can. J. Physiol. Pharmacol. 68: 642-645.

40. Kelly, D. and Coutts, A. G. P. 2000. Development of digestive and immunological function in neonates: role of early nutrition. Livest. Prod. Sci. 66: 161-167.

41. Koutsos, E. A. and Arias, V. J. 2006. Intestinal ecology: interactions among the gastrointestinal tract, nutrition, and the microflora. J. Appl. Poult. Res. 15: 161-173.

42. Lee, H. K., Song, J. H., Shin, C. S., Park, D. J., Park, K. S., Lee, K. U. and Koh, C. S. 1998. Decreased mitochondrial DNA content in peripheral blood precedes the development of non-insulin-dependent diabetes mellitus. Diabetes Res. Clin. Pract. 42: 161-167.

43. Lee, Y. Y., Park, K. S., Pak, Y. K. and Lee, H. K. 2005. The role of mitochondrial DNA in the development of type 2 diabetes caused by fetal malnutrition. J. Nutr. Biochem. 16: 195204.

44. Levitsky, D. A. and Strupp, B. J. 1995. Malnutrition and the brain: changing concepts, changing concerns. J. Nutr. 125: 2212-2220.

45. Limesand, S. W., Rozance, P. J., Smith, D. and Hay, Jr, W. W. 2007. Increased insulin sensitivity and maintenance of glucose utilization rates in fetal sheep with placental insufficiency and intrauterine growth restriction. Am. J. Physiol. Endocrinol. 
Metab. 293: 1716-1725.

46. Liu, J., Raine, A., Venables, P. H., Dalais, C. and Mednick, S. A. 2003. Malnutrition at age 3 years and lower cognitive ability at age 11 years: independence from psychosocial adversity. Arch. Pediatr. Adolesc. Med. 157: 593-600.

47. Liu, J. H., Raine, A., Venables, P. H. and Mednick, S. A. 2000. Malnutrition at age 3 years and externalizing behavior problems at ages 8,11 and 17 years. Am. J. Psychiatry 161: 20052013.

48. McLeod, K. I. and Liew, F. Y. 1975. Maternal protein deficiency and the immune response of the progeny in the rat. Proc. Nutr. Soc. 34: 41A-42A.

49. McMurray, D. N. 1984. Cell-mediated immunity in nutritional deficiency. Prog. Food Nutr. Sci. 8: 193-228

50. Mi, J., Law, C., Zhang, K. L., Osmond, C., Stein, C. and Barker, D. 2000. Effects of infant birthweight and maternal body mass index in pregnancy on components of the insulin resistance syndrome in China. Ann. Intern. Med. 132: 253-260.

51. Miranda, P. J., DeFronzo, R. A., Califf, R. M. and Guyton, J. R. 2005. Metabolic syndrome: Definition, pathophysiology, and mechanisms. Am. Heart J. 149: 33-45.

52. Monk, J. M., Makinen, K., Shrum, B. and Woodward, B. 2006. A brief communication: blood corticosterone concentration reaches critical illness levels early during acute malnutrition in the weanling mouse. Exp. Biol. Med. 231: 264-268.

53. Muniyappa, R., Montagnani, M., Koh, K. K. and Quon, M. J. 2007. Cardiovascular actions of insulin. Endocrinol. Rev. 28: 463-491.

54. Nelson, C. A., Bloom, F. E., Cameron, J. L., Amaral, D., Dahl, R. E. and Pine, D. 2002. An integrative, multidisciplinary approach to the study of brain-behavior relations in the context of typical and atypical development. Dev. Psychopathol. 14: 499-520.

55. Neu, J. 2001. Glutamine in the fetus and critically ill low birth weight neonate: metabolism and mechanism of action. J. Nutr. 131: $2585-2589$.

56. Niehaus, M. D., Moore, S. R., Patrick, P. D., Derr, L. L., Lorntz, B., Lima, A. A. and Guerrant, R. L. 2002. Early childhood diarrhea is associated with diminished cognitive function 4 to 7 years later in a northeast Brazilian shantytown. Am. J. Trop. Med. Hyg. 66: 590-593.

57. Nieto, N., Torres, M. I., Rios, A. and Gil, A. 2002. Dietary polyunsaturated fatty acids improve histological and biochemical alterations in rats with experimental ulcerative colitis. $J$. Nutr. 132: 11-19.

58. Ozanne, S. E., Jensen, C. B., Tingey, K. J., Storgaard, H., Madsbad, S. and Vaag, A. A. 2005. Low birthweight is associated with specific changes in muscle insulin-signalling protein expression. Diabetologia 48: 547-552.

59. Ozanne, S. E., Wang, C. L., Petry, C. J., Smith, J. M. and Hales, C. N. 1998. Ketosis resistance in the male offspring of protein-malnourished rat dams. Metabolism 47: 1450-1454.

60. Park, K. S., Kim, S. K., Kim, M. S., Cho, E. Y., Lee, J. H., Lee, K. U., Pak, Y. K. and Lee, H. K. 2003. Fetal and early postnatal protein malnutrition cause long-term changes in rat liver and muscle mitochondria. J. Nutr. 133: 3085-3090.

61. Penland, J. G. and Prohaska, J. R. 2004. Abnormal motor function persists following recovery from perinatal copper deficiency in rats. J. Nutr. 134: 1984-1988.

62. Petry, C. J., Dorling, M. W., Pawlak, D. B., Ozanne, S. E. and Hales, C. N. 2001. Diabetes in old male offspring of rat dams fed a reduced protein diet. Int. J. Exp. Diabetes Res. 2: 139143.
63. Petry, C. J. and Hales, C. N. 2000. Long-term effects on offspring of intrauterine exposure to deficits in nutrition. Hum. Reprod. Update. 6: 578-586.

64. Plagemann, A., Harder, T., Rake, A., Melchior, K., Rohde, W. and Dorner, G. 2000. Hypothalamic nuclei are malformed in weanling offspring of low protein malnourished rat dams. $J$. Nutr. 130: 2582-2589.

65. Pouta, A., Hartikainen, A. L., Sovio, U., Gissler, M., Laitinen, J., McCarthy, M. I., Ruokonen, A., Elliott, P. and Jarvelin, M. R. 2004. Manifestations of metabolic syndrome after hypertensive pregnancy. Hypertension 43: 825-831.

66. Quirk, G. J., Mejia, W. R., Hesse, H. and Su, H. 1995. Early malnutrition followed by nutritional restoration lowers the conduction velocity and excitability of the corticospinal tract. Brain Res. 670: 277-282.

67. Raine, A., Lencz, T., Bihrle, S., LaCasse, L. and Colletti, P. 2000. Reduced prefrontal gray matter volume and reduced autonomic activity in antisocial personality disorder. Arch. Gen. Psychiatry 57: 119-127.

68. Ramadhani, M. K., Grobbee, D. E., Bots, M. L., Cabezas, M. C., Vos, L. E., Oren, A. and Uiterwaal, C. S. P. M. 2006. Lower birth weight predicts metabolic syndrome in young adults: The Atherosclerosis Risk in Young Adults (ARYA)study. Atherosclerosis. 184: 21-27.

69. Ramakrishnan, U. 2002. Prevalence of micronutrient malnutrition worldwide. Nutr. Rev. 60: 46-52.

70. Rao, R., Tkac, I., Townsend, E. L., Gruetter, R. and Georgieff, M. K. 2003. Perinatal iron deficiency alters the neurochemical profile of the developing rat hippocampus. J. Nutr. 133: 32153221.

71. Reaven, G. M. 2003. Insulin resistance/compensatory hyperinsulinemia, essential hypertension, and cardiovascular disease. J. Clin. Endocrinol. Metab. 88: 2399-2403.

72. Reeds, P. J., Burrin, D. G., Stoll, B., Jahoor, F., Wykes, L., Henry, J. and Frazer, M. 1997. Enteral glutamate is the preferential source for mucosal glutathione synthesis in fed piglets. Am. J. Physiol. 273: 408-415.

73. Ricardo, O. S., Sandra, L. D. S., Rhowena, J., Barbosa, M., Isabelle, G., Jerome, L. B., Patrick, N., Raul, M. D. C. and Francisco, B. J. 2009. Perinatal undernutrition-induced obesity is independent of the developmental programming of feeding. Physiol. Behav. 96: 481-492.

74. Rigalleau, V., Beauvieux, M. C., Gallis, J. L., Gin, H., Schneiter, P. and Tappy, L. 2006. Effects of hyperglycemia on glucose metabolism before and after oral glucose ingestion in normal men. Am J. Physiol. Endocr. Metab. 290: 1198-1204.

75. Rojas-Castaneda, J., Vigueras-Villasenor, R. M., Rojas, P., Rojas, C. and Cintra, L. 2008. Immunoreactive vasoactive intestinal polypeptide and vasopressin cells after a protein malnutrition diet in the suprachiasmatic nucleus of the rat. Lab. Anim. 42: 360-368.

76. Santos, J. I. 1994. Nutrition, infection, and immunocompetence. Infect. Dis. Clin. North Am. 8: 243-267.

77. Schuler, S. L., Gurmini, J., Cecilio, W. A. C., de Azevedo, M. L. V., Olandoski, M. and de Noronha, L. 2008. Hepatic and thymic alterations in newborn offspring of malnourished rat dams. J. Parenter. Enter. Nutr. 32: 184-189.

78. Shahrabani-Gargir, L., Pandita, T. K. and Werner, H. 2004. Ataxia-telangiectasia mutated gene controls insulin-like growth factor I receptor gene expression in a deoxyribonucleic acid damage response pathway via mechanisms involving zincfinger transcription factors Sp1 and WT1. Endocrinology 145: 5679-5687. 
79. Snowden, A. W., Zhang, L., Urnov, F., Dent, C., Jouvenot, Y., Zhong, X., Rebar, E. J., Jamieson, A. C., Zhang, H. S., Tan, S., Case, C. C., Pabo, C. O., Wolffe, A. P. and Gregory, P. D. 2003. Repression of vascular endothelial growth factor A in glioblastoma cells using engineered zinc finger transcription factors. Cancer Res. 63: 8968-8976.

80. Southon, S., Gee, J. M., Bayliss, C. E., Wyatt, G. M., Horn, N. and Johnson, I. T. 1986. Intestinal microflora, morphology and enzyme activity in zinc-deficient and $\mathrm{Zn}$-supplemented rats. Br. J. Nutr. 55: 603-611.

81. Stead, J. D. H., Neal, C., Meng, F., Wang, Y., Evans, S., Vazquez, D. M., Watson, S. J. and Akil, H. 2006. Transcriptional profiling of the developing rat brain reveals that the most dramatic regional differentiation in gene expression occurs postpartum. J. Neurosci. 26: 345-353.

82. Thimmarayappa, J., Sun, J., Schultz, L. E., Dejkhamron, P., Lu, C., Giallongo, A., Merchant, J. L. and Menon, R. K. 2006. Inhibition of growth hormone receptor gene expression by saturated fatty acids: role of kruppel-like zinc finger factor, ZBP89. Mol. Endocrinol. 20: 2747-2760.

83. Thompson, R.A. and Nelson, C.A. 2001. Developmental science and the media: Early brain development. Am. Psychol. 56: $5-15$.

84. Thomson, C. D., Campbell, J. M., Skeaff, S. A., Miller, J. C. and Livingstone, V. 2008. Selenium and iodine supplementation in older New Zealanders. FASEB. J. 22: 146. 1.

85. Uni, Z., Zaiger, G., Gal-Garber, O., Pines, M., Rozenboim, I. and Reifen, R. 2000. Vitamin A deficiency interferes with proliferation and maturation of cells in the chicken small intestine. Br. Poult. Sci. 41: 410-415.

86. Valenzuela, A., Sanhueza, B. J. and Nieto, S. 2006. Docosahexaenoic acid (DHA), essentiality and requirements: why and how to provide supplementation. Grasas. Aceites 57: 229-237.

87. Wapnir, R. A. 2000. Zinc deficiency, malnutrition and the gastrointestinal tract. J. Nutr. 130: 1388-1392.

88. Wapnir, R. A., Garcia-Aranda, J. A., Mevorach, D. E. K. and
Lifshitz, F. 1985. Differential absorption of zinc and lowmolecular-weight ligands in the rat gut in protein-energy malnutrition. J. Nutr. 115: 900-908.

89. Ward, K. L., Tkac, I., Jing, Y., Felt, B., Beard, J., Connor, J., Schallert, T., Georgieff, M. K. and Rao, R. 2007. Gestational and lactational iron deficiency alters the developing striatal metabolome and associated behaviors in young rats. J. Nutr. 137: 1043-1049.

90. Wiggins, R. C., Fuller, G. N., Brizzee, L., Bissel, A. C. and Samorajski, T. 1984. Myelination of the rat optic nerve during postnatal undernourishment and recovery: a morphometric analysis. Brain Res. 308: 263-272.

91. Winick, M. and Rosso, P. 1969. The effect of severe early malnutrition on cellular growth of the human brain. Pediatr. Res. 3: $181-184$.

92. Wu, L. L., Zhang, L., Shao, J. and Zhao, Z. 2008. Effect of perinatal iron deficiency on behavioral developments and myelination abound the hippocampus in rats. Pediatrics 121: 155.

93. Yajnik, C. S., Deshpande, S. S., Jackson, A. A., Refsum, H., Rao, S., Fisher, D. J., Bhat, D. S., Naik, S. S., Coyaji, K. J., Joglekar, C. V., Joshi, N., Lubree, H. G., Deshpande, V. U., Rege, S. S. and Fall, C. H. 2008. Vitamin B12 and folate concentrations during pregnancy and insulin resistance in the offspring: the Pune Maternal Nutrition Study. Diabetologia 51: 29-38.

94. Zambrano, E., Martinez-Samayoa, P. M., Bautista, C. J., Deas, M., Guillen, L., Rodriguez-Gonzalez, G. L., Guzman, C., Larrea, F. and Nathanielsz, P. W. 2005. Sex differences in transgenerational alterations of growth and metabolism in progeny (F2) of female offspring (F1) of rats fed a low protein diet during pregnancy and lactation. J. Physiol. 566: 225-236.

95. Ziegler, T. R., Evans, M. E., Fernandez-Estivariz, C. and Jones, D. P. 2003. Trophic and cytoprotective nutrition for intestinal adaptation, mucosal repair, and barrier function. Annu. Rev. Nutr. 23: 229-261. 